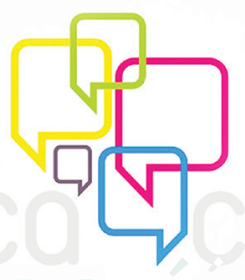

\title{
A ênfase emocional sobre movimentos sociais ${ }^{1}$
}

The emotional emphasis about social movements

El énfasis emocional sobre movimientos sociales

Maria Leonor CASTRO²

CASTELLS, Manuel. Redes de Indignação e Esperança: Movimentos sociais na era da internet. Rio de Janeiro: Zahar, 2013.

Nesta obra, o autor descreve a série de movimentos sociais que, segundo acredita, tiveram como característica a organização e coordenação através das redes sociais na internet. A nova configuração desses movimentos é a principal característica do século XXI.

Pelo fato da obra não ter um viés acadêmico, não caberia ao autor formular teorias acerca desses acontecimentos. Apenas lhe seria possível apresentar a investigação dos movimentos sociais da sociedade em rede. Para tanto, inicia com a exposição do caso da Tunísia e da Islândia, em seguida com a do Egito, da Espanha e, por último, dos Estados Unidos.

A forma em que a obra foi concebida nos leva à leitura de passagens extremamente detalhadas sobre as manifestações, principalmente a dos Indignados na Espanha (em que o autor participara ativamente) e do Occupy Wall Street (que, segundo o autor, teve características únicas frente às demais, como assembleias deliberativas nas praças). $\mathrm{O}$ excesso de descrição distrai o leitor para o principal ponto da obra, que é atentar para o quão revolucionário é o uso das redes sociais na internet para a coordenação, divulgação e organização dos movimentos sociais. De tanto em tanto, o autor volta com toda força à sua crença, enchendo os parágrafos com palavras que exaltam o tom dos movimentos. É como se ele voltasse a se recordar de dar o devido valor ao que postula com tanto vigor.

Os movimentos sociais nas redes sociais digitais aparecem para Castells como ponto crucial para diferenciar esses movimentos de outros no passado, pelo fato de terem auxiliado na divulgação dos eventos ao restante do mundo com imagens, vídeos, textos, páginas para serem seguidas no Twitter, Facebook etc. Apesar do tom revolucionário do autor ao tratar dos casos, é importante refletirmos acerca do que realmente esses movimentos significam. Eles foram tão grandes devido às redes sociais na internet ou os cidadãos de cada um dos países chegaram a um ponto em que estava insustentável viver e com o auxílio das redes fizeram esse

1 Resenha apresentada à sexta edição da Revista Ação Midiática - Estudos em Comunicação, Sociedade e Cultura, publicação ligada ao Programa de Pós-Graduação em Comunicação, da Universidade Federal do Paraná.

2 Mestranda em Ciência Política pela UFPR. leonordecastromaria@gmail.com 

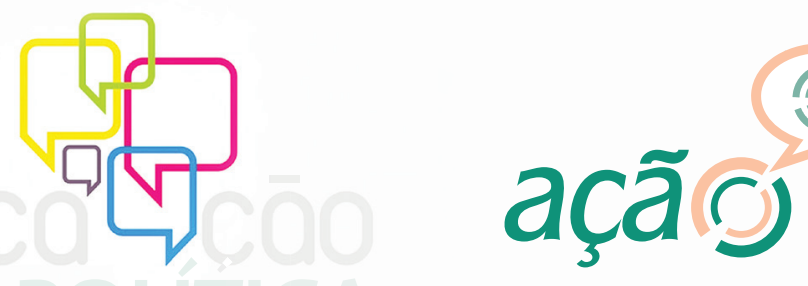

Estudos em Comunicação, Sociedade e Cultura

N. 6 | Ano 2013

Universidade Federal do Paraná | Programa de Pós-Graduação em Comunicação

uso tão intenso? É facilmente perceptível que uma revolução acabou influenciando a outra, mas é igualmente importante pensar sobre até que ponto outras forças externas aos movimentos, como a mídia, por exemplo, não foram peças estratégicas no enquadramento dos movimentos a fim de chamar atenção dos demais países. No caso da Primavera Árabe, a Al Jazeera foi de extrema importância para informação dos eventos.

De volta à obra, a Tunísia e a Islândia são postas no mesmo capítulo de análise pelo fato de serem em países genuinamente homogêneos no que diz respeito à constituição da população, língua, costumes etc. e também porque as manifestações levaram a algum tipo de mudança política ou econômica, segundo o autor. Não se está querendo dizer que nos demais países não houve alguma mudança, mas naqueles, efetivamente, se deu algum resultado concreto: na Tunísia o ditador Ben Ali sai do poder e, logo em seguida, já foram chamadas novas eleições, instituindo-se, assim, a democracia; na Islândia convocaram, por meio da internet, as pessoas à darem suas ideias a respeito da nova constituição (através de um método chamado de crowdsourcing), formulando-a assim, mais tarde por causa do endosso da população. Sobre a Islândia é relevante frisar que é um país de aproximadamente 320 mil habitantes, ou seja, muito pequeno e bastante coeso, que facilita bastante a elaboração da constituição com a colaboração dos cidadãos. Chega a ser absurdo pensar que o ocorrido na Islândia seja algo para se tomar como solução para os países árabes, por exemplo, que possuem populações muito maiores, havendo também uma diversidade étnica, religiosa e social extremamente grande.

Sobre os movimentos sociais nesses países, a revolução da Tunísia teve como início a indignação pelo fato de Mohamed Bouazizi, jovem vendedor de frutas que tinha suas mercadorias confiscadas pela polícia constantemente, ter incendiado o próprio corpo em forma de protesto contra as agressões que sofria quase diariamente pelas autoridades, e na Islândia foi a indignação frente ao colapso do sistema financeiro. Em ambos os países, segundo Castells, as redes foram de extrema importância para a disseminação de imagens e mensagens, oferecendo uma plataforma de discussão. Afirma que nesses casos o movimento passou do ciberespaço para o espaço urbano com a ocupação de praças e passeatas nas ruas.

Castells, portanto, julga necessário olhar para os seguintes movimentos sociais na tentativa de encontrar aqueles resultados alcançados tanto na Tunísia como na Islândia, pois acredita que se encontrarmos o mesmo padrão, estaríamos observando a ascensão de novas formas de transformação social. Descreve, assim, como as manifestações ocorreram no Egito, quais foram os atores, frisa a participação cada vez mais ativa e aparente das mulheres, como a Asman Mahfouz, autora de um vlog, que segundo Castells ficou conhecido como "O Vlog que Ajudou a Desencadear a Revolução". O dia que ficou marcado na história egípcia é o dia 25 de janeiro de 2011, o primeiro dia das manifestações e concentração do acampamento na Praça Tahrir. 

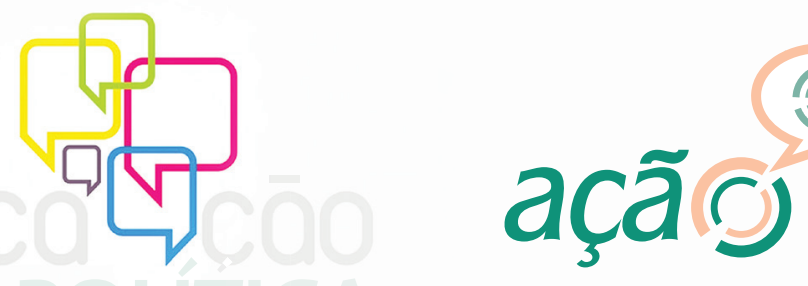

Estudos em Comunicação, Sociedade e Cultura

N. 6 | Ano 2013

Universidade Federal do Paraná | Programa de Pós-Graduação em Comunicação

Sobre os "Indignados" na Espanha, o autor descreve minuciosamente cada acontecimento e praticamente faz o leitor se transportar para as ruas da Espanha, bem como sentir o que os manifestantes experimentavam no momento dos gritos e caminhadas. Tem-se a impressão de que Castells, a todo momento, quer que o leitor se perceba em cena e participe dessa nova fase dos movimentos sociais. Da mesma forma ele faz com o movimento Occupy.

Na edição brasileira, fez um posfácio dizendo que os movimentos sociais nas redes na era da internet também ocorreram no Brasil, pois justamente enquanto fazia visita ao Brasil, ocorreram as manifestações nas ruas de São Paulo. Chamou atenção às respostas das instituições políticas, que até o momento tanto o governo de São Paulo como o de Brasília haviam reprimido e criticado duramente as manifestações.

Para avaliar a ação dos movimentos sociais, o autor parte do princípio de que esses são frutos de indignação e insatisfação dos indivíduos, que através do contrapoder gerado pela percepção do poder coercitivo por parte do governo, conseguem insurgir-se e alcançar seus objetivos. Tem-se a impressão, ao ler certos trechos, de que os movimentos surgem por indignações, que são postadas na internet e em forma de eventos de protestos, depois o apelo nas ruas, trazendo a esperança de que tudo pode mudar para o melhor e o resultado, que parece ser sempre positivo. Apesar de mostrar que o evento no Egito não resultou ainda na democracia tão esperada, tem-se a impressão de que só o fato de terem se organizado através da internet, que levou centenas de milhares às ruas, já é um resultado positivo.

A internet é uma ferramenta que pode auxiliar no debate em voga, assim como organização de eventos de manifestações nas ruas, mas há registros na história de que muitos movimentos surgiram antes da existência da internet, o que leva a muitos pesquisadores a rejeitar essa visão tão positiva da internet, como a do Castells. De fato, muitos movimentos podem ter tido registros de vídeos e imagens, mas o que acontece na rede não se passa nas ruas, nem o que se passa nas ruas reflete-se perfeitamente nas redes. O espaço urbano, com toda a repressão policial e militar é extremamente característico; já nas redes tudo ocorre sem essas repressões tão violentas (nem físicas elas são), os manifestos ficam restritos aos usuários das redes e àqueles que seguem os perfis dos outros usuários.

Por fim, o conjunto da obra é interessante pela quantidade de detalhes que traz ao leitor, bem como fontes únicas sobre informações dos movimentos, assim como dados e entrevistas que não são tão fáceis de captar e condensar em um único estudo. Contudo, o autor se utiliza de muitos jargões exageradamente positivos em relação ao uso da internet para a organização, coordenação e comunicação dos movimentos sociais. Há que se tomar cuidado para não resvalar para o lado emocional que esses movimentos nos levam, pois estão carregados de ira, raiva, insatisfação e indignação, e podem fazer o pesquisador perder o foco ao olhar para os movimentos. 